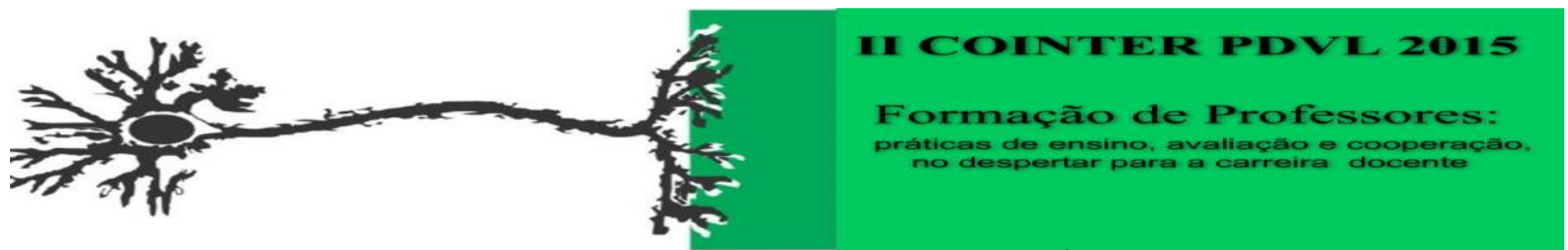

\title{
EXPERIMENTOS INVESTIGATIVOS NO ENSINO DE QUÍMICA: QUAL INDICADOR ÁCIDO E BASE NATURAL É MAIS EFICAZ?
}

Apresentação: Comunicação Oral

\author{
Fernando Cleyton Henrique de Mendonça Silva ${ }^{1}$; Douglas Salgado da Silva ${ }^{2}$; Kilma da Silva Lima \\ Viana $^{3}$; Wlisses Guimarães Souza ${ }^{4}$
}

\begin{abstract}
Resumo
O uso de experimentos investigativos é uma das estratégias sugeridas para permitir a participação mais ativa dos alunos no processo de aprendizagem. $\mathrm{O}$ mesmo tem uma forte contribuição para o desenvolvimento das habilidades cognitivas dos alunos, uma vez que o estudante passa a ter uma maior participação nas aulas de Química. Com isso, o presente artigo tem como objetivo o relato das análises realizadas sobre as possíveis contribuições que os experimentos investigativos podem proporcionar aos alunos. Utilizou-se como campo de pesquisa estudantes do curso de licenciatura em química do IFPE campus Vitória. O trabalho faz parte do programa PDVL(Programa Internacional Despertando Vocações para as Licenciaturas) e foi desenvolvido a partir de um de seus subprojetos Kits Experimentais para o Ensino de Química do IFPE. O experimento escolhido foi indicador ácido e base naturais e os estudantes tinham a tarefa de investigar quais deles era o mais eficaz, foi utilizado como incentivo para os alunos uma problematização aos mesmos em forma de e-mail fictício de uma indústria qualquer onde nele estava um pedido de analise dos indicadores. Como resultados obtidos, constatamos que a abordagem investigativa experimental quando trabalhada de maneira correta contribui significativamente para o desenvolvimento cognitivo da maioria dos alunos. Além disso, o experimento colaborou com a relação aluno/aluno, pois os mesmos realizaram a prática a todo o momento em equipe e tiveram de discutir e entrar em acordos. Contudo são encontradas muitas dificuldades para a realização dessa prática e por isso a mesma não e muito utilizada pelos professores atualmente.
\end{abstract}

Palavras-Chave: Ensino de Química, Investigação, Alunos Ativos.

\section{Introdução}

Ácidos e Bases são substâncias químicas que possuem grande importância em nossa vida uma vez que está presente em nosso dia a dia nos alimentos, material de limpeza, higiene, remédios e cosméticos. Também são matérias primas indispensáveis em grande parte de produtos industriais. Existem várias definições de ácido e base dentre elas a mais conhecida é a de Svante August Arrhenius, físico, matemático e químico sueco, criador da teoria da dissociação eletrônica, ele dizia que quando dissolvido em água o ácido libera íons positivos de hidrogênio $\left(\mathrm{H}^{+}\right)$, já a base em água libera íons negativos, hidroxilas $\left(\mathrm{OH}^{-}\right)$.

Ácido dissolvido em água:

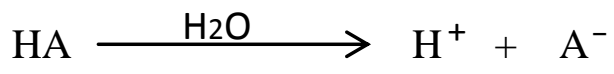

\footnotetext{
${ }^{1}$ Licenciatura em Química, IFPE- campus Vitória de Santo Antão, silva.fchm@gmail.com

${ }^{2}$ Licenciatura em Química, IFPE- campus Vitória de Santo Antão, douglassalgado525@gmail.com

${ }^{3}$ Doutora em ensino de Ciências(Física e Química), Professora do IFPE, kilma.viana@vitoria.ifpe.edu.br

${ }^{4}$ Mestre em Ensino de Ciências, Professor do IFPE, wlisses.guimaraes@vitoria.ifpe.edu.br
} 
Base dissolvida em água:<smiles></smiles>

Com a presença de ácidos e bases em nosso cotidiano viu-se a necessidade de conceber indicadores para conseguir identifica-los. Esses indicadores nada mais são do que substâncias orgânicas que ao entrar em contato com meios ácidos ou alcalinos se unem aos íons $\mathrm{H}^{+}$e $\mathrm{OH}^{-} \mathrm{e}$ mudam de cor devido a uma alteração em sua configuração eletrônica. Essa união se dá por que geralmente os indicadores são ácidos ou bases fracas fazendo com que facilite essa reação, alguns exemplos de indicadores são a fenoftaleína, o alaranjado de metila e o azul de bromotimol.

Existem também os chamados indicadores naturais que são pigmentos conhecidos como antocianinas, eles são solúveis em água e extraídos de animais e vegetais, essas antocianinas são bastante sensíveis as alterações de $\mathrm{pH}$ do meio. Elas são responsáveis por dar coloração às plantas partindo da cor vermelha ate a tonalidade azul.

As antocianinas são responsáveis por mudar de coloração em meio ácido e em meio básico tornando possível identificar o $\mathrm{pH}$ da solução, alguns exemplos de vegetais que existe a presença dessa antocianina são o repolho roxo, beterraba, ameixa, papoula, o feijão preto entre outros. Um fato interessante é que a cor das pétalas de algumas flores pode mudar conforme a composição do solo.

Esses indicadores naturais podem ser usados nas aulas de química para identificar o $\mathrm{pH}$ de substâncias ácidas e básicas. As práticas experimentais estão cada vez mais presentes no ensino de química, porem em sua maioria são executas de maneira acrítica e observacional tornando assim as aulas menos produtivas. Nesse processo o professor é detentor do conhecimento e os estudantes são excluídos das analises, elaboração de hipóteses e ate mesmo da execução do experimento, colocando-os em uma postura passiva onde devem seguir os passos pré-estabelecidos à risca. Fica claro a necessidade de se investir na proposição de metodologias e estratégias capazes de proporcionar o desenvolvimento cognitivo do aluno, e a experimentação em química pode contribuir para que esse objetivo possa se concretizar. (SUART e MARCONDES, 2008).

A experimentação pode sim contribuir com bons resultados de estudantes nas aulas de química, para isso tornar o aluno protagonista nesse processo de ensino e aprendizagem é o objetivo a ser buscado. É evidente que quando os professores deixam de ser detentores do saber e passam a mediar seus estudantes levando-os a buscar o conhecimento, através de questionamentos e pesquisas, fazendo com que os próprios construam suas hipóteses levam os discentes a uma aprendizagem mais profunda e espontânea. A experimentação se mostra um excelente instrumento capaz de acabar com a postura passiva dos alunos no sistema educacional. (PINHO ALVEZ, 2000).

\section{Fundamentação Teórica}

\subsection{Experimentos Investigativos no Ensino de Química}

Existem várias metodologias em que a experimentação pode ser trabalha, porém grande parte delas consegue com êxito tornar as aulas de química mais atraentes e interessantes para o estudante deixando um pouco a desejar quando se é olhado as possíveis contribuições que elas podem trazer para a aprendizagem do aluno. A experimentação investigativa por sua vez tem o proposito de unir essas duas coisas, para Pinho Alvez (2000) a participação ativa do aluno em situação de investigação, proposta na forma de desafio, o instigará na busca de uma resposta através de hipóteses e pesquisas, tornando a aula mais atraente e contribuindo simultaneamente com a aprendizagem do aluno.

Outras formas de desenvolver atividades experimentais diferente dessa pouco contribuem com o desenvolvimento cognitivo, com a construção de conceitos químicos e com a formação de habilidades essenciais para o exercício da cidadania pelos alunos. De acordo com Gil-Pérez et al., 
(2005, p. 25) aprendizagem no ensino de ciências e os aspectos éticos e sociais devem caminhar juntos.

Segundo Hofstein e Lunetta (2004), a experimentação de modo investigativo torna os alunos ativos, interpretativos e interativos, fazendo com os mesmos construam seu próprio conhecimento a partir da resolução de problemas. Os experimentos investigativos se diferenciam por trabalhar com a ideia construtivista de que os estudantes já vão para escola com conhecimentos prévios. Com isso uma prática investigativa é caracterizada por tornar os alunos mais ativos durantes as aulas, uma vez que o professor tem o papel de mediar a experimentação levando os estudantes a construir seu próprio conhecimento.

A experimentação investigativa se realizada da maneira correta muito contribui com o desenvolvimento cognitivo dos estudantes. Para isso a atividade deve estar acompanhada de problemas, questionamentos, diálogos, envolvendo tudo isso com a introdução de conceitos, (CARVALHO et al. 1999. P.42). Esses problemas devem estar ligados aos conceitos químicos que os alunos precisam aprender. Para a resolução desses problemas os alunos normalmente entram em debate com seu grupo levantando hipóteses e argumentos, transcrevem tudo que acham necessário, e testam suas teorias no experimento, isso contribui significativamente com o aprimoramento dos aspectos cognitivos dos mesmos além de colaborar com o seu ensino e aprendizagem.

\section{Metodologia}

\subsection{Caracterização}

Este trabalho faz parte do programa PDVL (Programa Despertando Vocações para as Licenciaturas) e foi desenvolvido a partir do subprojeto Kits Experimentais para o Ensino de Química do IFPE, o trabalho foi desenvolvido em laboratório durante a aula de Prática da Química III e aborda o conteúdo de ácido, base, indicadores naturais e $\mathrm{pH} / \mathrm{pOH}$.

\subsection{Tipos de Pesquisa}

O trabalho tem uma abordagem qualitativa uma vez que houve a aplicação da intervenção e foram colhidos dados através de questionários, relatos e analise do que foi escrito pelos alunos durante a realização do experimento.

\subsection{Público}

Uma turma do $3^{\circ}$ período de graduação do curso de Licenciatura em Química do IFPE campus Vitória de Santo Antão, com cerca de 15 alunos.

\subsection{Materiais}

- $50 \mathrm{ml}$ de HCL a $0.1 \mathrm{M}$;

- $50 \mathrm{ml}$ de $\mathrm{NaOH}$ a $0.1 \mathrm{M}$;

- $1000 \mathrm{ml}$ de água destilada;

- 21 tubos de ensaio com tampa;

- 3 Pipetas de $5 \mathrm{ml}$;

- 9 mini pipetas;

- 3 Suportes para tubos de ensaio (que caiba 7 tubos cada um);

- 6 béqueres de $50 \mathrm{ml}$;

- Repolho roxo, feijão preto e papoula (Hibiscus sp.);

- Três peneiras finas. 


\subsection{Métodos}

A intervenção foi realizada em três passos.

Passo 1:

A prática começou com a apresentação da problematização que se deu por meio de um email fictício enviado por uma indústria a qual pedia para os alunos descobrirem qual o indicador ácido base natural era mais eficaz para que pudessem diminuir gastos e baratear o seu produto.

\section{E-mail}

$\begin{array}{ll}\text { De: empresa.produtos.clean@gamail.com } & \text { Data de envio: 18/08/2015 as 13:45 } \\ \text { Para: analises.ifpe.@gmail.com } & \text { Recebido em: 19/08/2015 as 16:00 }\end{array}$

Boa tarde.

Nós da empresa Produtos Cleanestamos comproblemas quanto a análise de algumas características, inclusive de $\mathrm{pH}$, de alguns dos nossos produtos, pois os indica dores á cido-base que dispomos são de alto custoe a cabam por encarecer os produtos.

Estamos entrando em contato comvocês para que possam fazer uma análise sobre os seguintes indicadores ácido-basenaturais, pois são mais rentáveis, e nos respostar com aquele que for mais eficiente.

Indicadores extraídos do: Repolho roxo, Feijão preto e Papoula (Hibiscus sp.).

Estamos no aguardo.

Att. Equipe Técnica.

Figura 1: Problemática apresentada para turma.

Passo 2:

A extração da antocianina dos vegetais, para isso foram usados os métodos que melhor se adequou ao tipo de vegetal usado, esses métodos podem ser o aquecimento do vegetal que é o caso do feijão preto que quando aquecido solta sua antocianina, ou o método de macerar o vegetal, que é normalmente usado com o repolho roxo.

Após a extração das antocianinas de seus respectivos vegetais cada grupo fez uma escala de $\mathrm{pH}$ em tubos de ensaio partindo do 1 ao 13 utilizando apenas os números impares. Para a escala foi utilizado Ácido Clorídrico e Hidróxido de Sódio com concentração de 0,1M, onde no primeiro tubo 
de $\mathrm{pH} 1$ foi colocado $5 \mathrm{ml}$ de $\mathrm{HCl}$, no de $\mathrm{pH} 3$ foi colocado $5 \mathrm{ml}$ de água destilada mais uma gota de $\mathrm{HCl}$ com concentração de $0,1 \mathrm{M}$, no tubo de $\mathrm{pH} 5$ foi colocado $5 \mathrm{ml}$ de água destilada mas uma gota da solução do tudo de $\mathrm{pH} \mathrm{3,} \mathrm{no} \mathrm{tubo} \mathrm{de} \mathrm{pH} 7$ foi colocado $5 \mathrm{ml}$ de água destilada. $\mathrm{O}$ mesmo procedimento foi realizado com a base $(\mathrm{NaOH})$, no tubo de $\mathrm{pH} 13$ foi colocado $5 \mathrm{ml}$ de $\mathrm{NaOH}$ com concentração de $0,1 \mathrm{M}$, no de $\mathrm{pH} 11$ colocou-se $5 \mathrm{ml}$ de água destilada mas uma gota de hidróxido de sódio a $0,1 \mathrm{M}$ e assim se repetiu ate o de $\mathrm{pH}$ 9. Para se chegar a essa escala o calculo utilizado esta exemplificado abaixo.

\begin{tabular}{|c|c|}
\hline $\begin{aligned} 1 & {\left[\mathrm{H}^{+}\right]=10^{-6} \mathrm{~mol} \mathrm{~L}^{-1} } \\
& \mathrm{pH}=-\log \left[\mathrm{H}^{+}\right] \\
\mathrm{pH} & =-\log 10^{-6} \\
& \mathrm{pH}=-(-6) \underbrace{\log 10}\end{aligned}$ & $\begin{aligned} 2 & {\left[\mathrm{OH}^{-}\right]=10^{-5} \mathrm{~mol} \mathrm{~L}^{-1} } \\
& \mathrm{pOH}=-\log \left[\mathrm{OH}^{-}\right] \\
& \mathrm{pOH}=-\log 10^{-5} \\
& \mathrm{pOH}=-(-5) \underbrace{\log 10}\end{aligned}$ \\
\hline $\mathrm{pH}=6$ & $\mathrm{pOH}=5$ \\
\hline $\begin{array}{l}\text { Assim: } \\
{\left[\mathrm{H}^{+}\right]=10^{-6} \mathrm{~mol} \mathrm{~L}^{-1}} \\
\mathrm{pH}=6\end{array}$ & $\begin{array}{l}\text { Assim: } \\
{\left[\mathrm{OH}^{-}\right]=10-5 \mathrm{~mol} \mathrm{~L}^{-1}} \\
\mathrm{pOH}=5\end{array}$ \\
\hline
\end{tabular}

Figura 2: Fórmula para calculo de pH.

Após ter feito a escala de $\mathrm{pH}$ os grupos pingaram aproximadamente 5 gotas do indicador anteriormente extraído do seu respectivo vegetal e observaram o que aconteceu.

Passo 3:

Após ter feito os dois passos anteriores, os experimentos de todos os grupos foram colocados juntos para que os estudantes pudessem analisar e debater com seu grupo qual dos indicadores naturais foi o mais eficaz para a determinação de $\mathrm{pH}$. O professor por sua vez em hipótese alguma sugeriria ou disse qual deles é o melhor, os alunos tiveram que descobrir por si só. Por fim cada grupo teve que transcrever em um papel o seu argumento, o porquê que eles defendem que aquele indicador é o melhor e tiveram que apresentar para a o professor e toda turma.

\section{Resultados e Discussão}

Após a intervenção do experimento pôde-se perceber que a experimentação investigativa contribuiu significativamente com o desenvolvimento cognitivo dos estudantes, uma vez que conseguiu tomar a atenção do aluno e fez com que os mesmos saíssem de sua zona de conforto e passassem a investigar qual dos indicadores era o mais eficaz. Um dos principais fatores que contribuiu com o sucesso dessa intervenção foi a problematização que serviu como um incentivo para os mesmos. chegar:

A seguir serão apresentadas algumas conclusões em que dois dos grupos conseguiram Grupo A: 
"Achamos que o melhor indicador é o feijão preto, pois a visualização está bem diferenciada podendo assim caracterizar claramente cada pH, é o mais o mais próximo da escala. E também porque todas as cores tem uma tonalidade característica nenhuma é igual a outra para com isso poder dar uma precisão maior a quem faz o experimento."

Grupo B:

"Podemos analisar que o indicador ácido-base do repolho roxo foi visualmente mais eficiente em comparação aos indicadores de feijão preto e de hibiscos, pois a tonalidade das cores facilitou a percepção do $\mathrm{pH}$. Uma vez que os pHs próximos como 1 e 3 dos dois indicadores nõ apresentam diferenças relevantes de tonalidade."

$\mathrm{O}$ experimento desencadeou posturas ativas nos alunos uma vez que os mesmos participaram diretamente da realização do experimento tendo somente o auxilio do professor. Esse tipo de experimento aumentou as possibilidades de aprendizagem dos alunos, pois tudo que aconteceu foi imprevisível e o professor se mostrou preparado quando a todo o momento questionava os discentes forçando-os a pensar e a encontrar soluções para as dúvidas que iam se apresentando.

De acordo com o questionário aplicado antes e após a intervenção pode-se constatar que $66,66 \%$ conheciam a abordagem investigativa e que durante o ensino médio $91,66 \%$ dos alunos não tinham aulas experimentais com essa abordagem.

\section{Conhecimento sobre experimentos Investigativos}

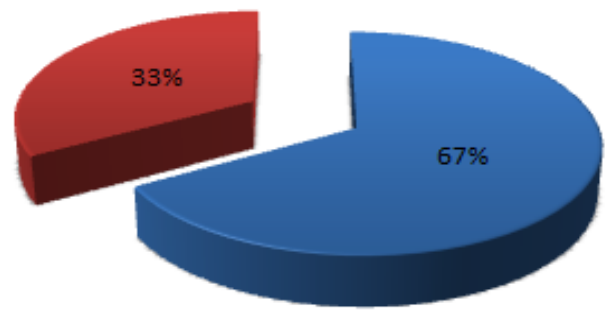

Conhecia a abordagem investig ativa

QNão conhecia a abordagem investigativa

Gráfico 1: Conhecimentos sobre experimentos Investigativos.

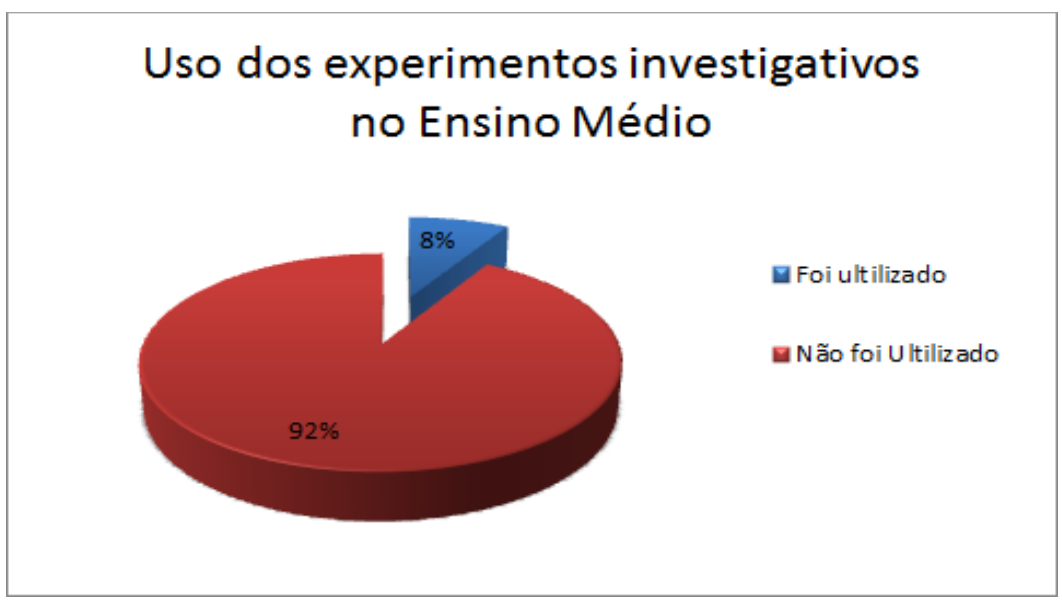

Gráfico 2: Utilização dos Experimentos Investigativos no ensino médio 
De acordo com os alunos os experimentos investigativos contribuíram diretamente com o seu desenvolvimento cognitivo, sua socialização, visto que tiveram de trabalhar em equipe para realizar a prática com precisão, e com uma maior participação na aula.

A seguir será citada a resposta de um dos alunos presente no questionário:

"Os experimentos investigativos pode proporcionar ao aluno uma postura mais ativa, além de promover a criticidade e um olhar científico no aluno, contribuindo para seu processo de ensino aprendizagem."

Contudo muitas dificuldades são encontradas pelos professores principalmente da rede pública de ensino, algumas delas são facilmente identificadas como a falta de tempo para realizar a prática, a falta de um local adequado, a falta de recursos e materiais e ate mesmo a falta de interesse do professor uma vez que o mesmo precisa sair de sua zona de conforto e está preparado a várias situações que podem ser apresentadas.

Sendo professores em formação, os alunos foram questionados quanto a isso e grande parte deles tiveram uma resposta homogenia que pode ser exemplificada com a apresentada a seguir:

"Inicialmente a abordagem investigativa demanda de um tempo maior para o professor organizar sua sequencia didática. Além de um domínio do conteúdo para mediar e guiar o estudante para o conhecimento solidificado baseado nas experiências prévias confrontadas com o ensino sistematizado".

\section{Conclusões}

Concluímos que as atividades experimentais de caractere investigativo quando trabalhadas de maneira correta contribuem de maneira direta com a construção de conceitos químicos, além de tornar os alunos mais ativos durante as aulas uma vez que os mesmos são estimulados a solucionar problemas que estão ligados aos seu dia a dia. Além disso, o experimento colaborou com a relação aluno/aluno, pois os mesmos realizaram a prática a todo o momento em equipe e tiveram de discutir e entrar em acordos. Contudo são encontradas muitas dificuldades para a realização dessa prática e por isso a mesma não e muito utilizada pelos professores atualmente.

\section{Referências}

SUART, R. C; MARCONDES, M. E. R. Atividades experimentais investigativas: habilidades cognitivas manifestadas por alunos do ensino médio. XIV Encontro Nacional de Ensino de Química. Curitiba, p.1-12, jul. 2008.

PINHO ALVEZ, J. Atividades experimentais: do método à prática construtivista. 2000. 312 f. Tese (Doutorado em Educação). Centro de Ciências da Educação, Universidade Federal de Santa Catarina, Florianópolis, 2000.

GIL-PÉREZ, D.; et al. A Necessária Renovação do Ensino das Ciências. São Paulo: Cortez Editora, 2005 p. 263.

HOFSTEIN, A.; LUNETTA, V. The laboratory in Science education: foundations for twenty-first century. Science Education, 88, p.28-54, 2004. 
CARVAlHO, A. M. P. ; SANTOS, E. I. ; AZEVEDO M. C. P. S. ; DATE, M. P. S. ; FUJII, S.R.S.;NASCIMENTO,V. B.(1999). Termodinâmica: Um ensino por investigação. 1. ed. São Paulo: Universidade de São Paulo - Faculdade de Educação, 1999. 